\title{
Malathion induced testicular toxicity and oxidative damage in male mice: the protective effect of curcumin
}

\author{
Rehab Ibrahim Ali, ${ }^{1,2}$ and Mahrous Abdelbasset Ibrahim ${ }^{3,4^{*}}$ (D)
}

\begin{abstract}
Background: The organophosphorus (OP) pesticide malathion is a highly neurotoxic compound, leading to cholinergic syndrome. Malathion produces reproductive toxicity.

Objectives: To investigate the protective effects of curcumin on the testicular toxicity induced in male mice orally administrated with malathion.

Materials and methods: Forty-eight mature male mice were used. The mice were divided into four groups, 12 mice each, and treated for 4 weeks as follows: the control (G1), curcumin-treated group (G2), malathiontreated group (G3), and the curcumin plus malathion-treated group (G4). At the end of the experiment, the mice were sacrificed and dissected, and tissue samples were obtained and antioxidant parameters were examined. Tissue samples were also histopathologicaly and immunohistochemically assessed. Samples of blood were collected for assessing the levels of serum hormones, namely follicle-stimulating hormone (FSH), luteinizing hormone (LH), testosterone, and acetylcholinesterase activity (AChE).

Results: Malathion exposure caused a decrease in serum testosterone and LH levels and antioxidant enzymes (SOD and CAT) and elevation of oxidative stress marker (MDA). Histological changes were as well observed in the form of maturation abnormalities, intratubular necrosis, and inflammatory infiltrate in malathion-treated mice. Co-administration of curcumin with malathion reduced lipid peroxidation (LPO) activity and improved spermatogenesis and increased catalase (CAT), superoxide dismutase (SOD), and testosterone levels.

Conclusion: The current study showed that curcumin could ameliorate the elevated concentration of lipid peroxidation products, increase the levels of antioxidative markers, and improve the pathological changes in the testis induced by malathion administration. The capacity of curcumin to work as antioxidant supposedly relates to its structure.
\end{abstract}

Keywords: Malathion, Toxicity, Curcumin, Oxidative stress, Testis

\section{Background}

The widespread use of the organophosphorus (OP) pesticide (malathion) in agricultural and household applications and the high rates of food contamination can lead to exposure of humans to high levels of this toxic chemical (Babu et al. 2006; dos Santos et al. 2011; Salama et al. 2015; Ibrahim et al. 2011).

\footnotetext{
* Correspondence: Mahrous.ibrahim@med.suez.edu.eg

${ }^{3}$ Forensic Medicine and Clinical Toxicology Department, College of Medicine, Jouf University, P.O box.2014, Aljouf Postal Code: 42421, Saudi Arabia

${ }^{4}$ Forensic Medicine and Clinical Toxicology Department, Faculty of Medicine, Suez Canal University (SCU), Ismailia Postal Code: 41522, Egypt

Full list of author information is available at the end of the article
}

Exposure to malathion [O, O-dimethyl-S-(1,2-dicarbethoxyethyl) phosphorodithioate] causes distinct cytopathological and histopathological changes in the male mammal's reproductive system. Uzunhisarcikli et al. reported that the duration and concentration of exposure to malathion have the major role of these changes that include higher percentage of sperm abnormality, defects in spermatogenesis, and lowered sperm count (Mahgoub and El-Medany 2001; Bustos-Obregón and GonzálezHormazabal 2003; Uzunhisarcikli et al. 2007). Geng et al. found in addition marked loss of the testis weights, final body weight, and sperm mobility (Geng et al. 2015). 
The ability of organophosphorus compounds including malathion to cross the blood-testis barrier accounts for the damage that affect the testis (Nahid et al. 2016). The testicular biological membranes are damaged by malathion through oxidative stress mechanism and lipid peroxidation induction (Geng et al. 2015).

Leydig and spermatogenic cell degeneration might occur in this condition as a result of the oxidative damage, which decreases the sperm counts and deactivates spermatogenesis (Uzunhisarcikli et al. 2007; Penna-Videau et al. 2012). Penna-Videau and his colleagues reported that steroidogenesis is impaired by malathion exposure and this in turn stimulates the proliferation of the seminiferous epithelium beside the apoptosis that affect germ cells (Penna-Videau et al. 2012). Moreover, reduced chromatin and damaged DNA can be caused by malathion exposure that affect the maturation of spermatogenic cells in mice in its late stages (Ojha and Srivastava 2014; Moore et al. 2011). The structure of the microtubules and mitochondrial enzymes of the sperm could be affected and injured by the oxidative damage induced by OPs that affects and destroys the sperm. Latchoumycandane et al. reported previously that the functions of the sperm and their mobility are reduced, causing infertility because of reactive oxygen species generation (Latchoumycandane et al. 2002).

Previous researchers have identified the mechanism of testicular damage induced by malathion exposure in rats and humans: first, because of the lipophilic feature of malathion which in turn facilitates its prompt tissue diffusion. This diffusion causes accumulation of acetylcholine in the target organ causing all the manifestations of OP poisoning (Bajgar 2005). Induction of the oxidative stress damage with the generation of reactive oxygen species (ROS) and the loss of balance between the oxidant/antioxidant systems are another way of organ damage by malathion (Bayrami et al. 2012).

Oxidative stress might be relieved by using antioxidant therapy. Recently, there is a major inclination toward the utilization of natural products as antioxidant agents. This pattern requires the assessment of the pharmaceutical properties of these natural products (Sepand et al. 2013; Kim et al. 2018; Huang et al. 2018; Ibrahim et al. 2018). Curcumin (diferuloylmethane), a polyphenol, is the active component of the condiment turmeric (Curcuma longa) and has been used for treatment purposes for hundreds of decades (Gupta et al. 2012; Joint 2003; Bulku et al. 2012). It acts as a free radical scavenger and antioxidant (Ak and Gülçin 2008) inhibiting lipid peroxidation and oxidative DNA damage and enhances the activities of antioxidant enzymes such as glutathione-S-transferase (Piper et al. 1998). Its free radical scavenging antioxidant property helps it in reducing genotoxic damage caused by organophosphorus exposure (Kumar et al. 2014).

Curcumin has been used in clinical trials as anticancer agents with its activity resulting from multiple biochemical mechanisms. Studies have shown that this compound can inhibit the malignant proliferation of tumor cells and enhance chemosensitivity of liver cancer, gastric cancer, and colon cancer (Kunati et al. 2018; Gall Troselj and Kujundzic 2014).

The protective effect of curcumin has been investigated against the effect of many OP compounds on several organs (Hassani et al. 2015). This study was designed to evaluate the protective activity of curcumin on malathion-induced testicular toxicity in male mice by assessment of histopathological changes of the testis, oxidative markers, plasma testosterone level, and plasma acetylcholinesterase activity.

\section{Materials and methods}

Experimental animals

Forty-eight sexually mature male Swiss albino mice, $\sim 2$ months in age (weighing approximately 20-30 g), were utilized in this study. Plastic cages were used for housing of the animals (six mice in each), and a standard laboratory diet was used for the fed of mice with water ad libitum. The mice were maintained at a laboratory temperature of $20 \pm 2 / \mathrm{C}$ and exposed to a 12-h light/dark cycle. Before beginning the experiments, the mice were quarantined for 10 days.

\section{Chemical items}

a) Malathion: high technical grade (98\% purity), was purchased from the branch of the Ministry of Agriculture, Egypt. All the utilized solvents in this research were of high grade and were purchased from Sigma Chemical Company (St. Luis, MO, USA).

b) Curcumin powder: supplies as orange powder, molecular formula [HOC6H3 (OCH3)

$\mathrm{CH}=\mathrm{CHCO}] 2 \mathrm{CH} 2$, molecular weight $368.38 \mathrm{~g} /$ mol and stored at room temperature (provided by Sekem's Company, Cairo, Egypt). A Soxhlet apparatus was used to extract the curcumin from the turmeric powder. Filter paper was used to filter the extract, and a rotary evaporator was utilized to evaporate the solvent; then, an oven at $40^{\circ} \mathrm{C}$ for $24 \mathrm{~h}$ was used to dehydrate the resultant extract and left at $4{ }^{\circ} \mathrm{C}$ until use. Then, the extract was concentrated and lyophilized in a freeze dryer. Five grams of curcumin was produced from $100 \mathrm{~g}$ of turmeric (Deters et al. 2000). 
c) Kits: MDA, malondialdehyde; SOD, superoxide dismutase; CAT, catalase; GSH, glutathione; GPx, glutathione peroxidase; LH, luteinizing hormone; and $\mathrm{FSH}$, follicle-stimulating hormone; and testosterone were purchased from Sigma Chemical Company (St. Luis, MO, USA).

\section{Animal treatment schedule}

The mice were divided into two groups, namely, the control $(n=12)$ and experiment groups $(n=36)$. The mice in the experiment group were divided into three groups, namely, the curcumin-treated group $(n=12)$, the malathion-treated group $(n=12)$, and the curcumin plus malathion-treated group $(n=12)$. All the materials were given to mice every morning (between 09:00 and 10:00 h). The first day of animal treatment was considered as day 0 . At the end of the period of experiment (4 weeks), the mice in each group were sacrificed and dissected, and the testes were extracted and antioxidant parameters were assessed. Sections from the testes were also subjected to histopathological and immunohistochemical assessment. Samples of blood were obtained to assess the follicle-stimulating hormone (FSH) level in the serum, with luteinizing hormone (LH) level, and testosterone level. In addition, acetylcholinesterase activity (AChE) was examined.

\section{Control group (G1)}

Corn oil at a dose of $0.2 \mathrm{ml}$ per animal was given via gavage, once a day for the total period of experiment.

\section{Curcumin-treated group (G2)}

Once a day, the mice were given curcumin and corn oil orally at a dose of $200 \mathrm{mg} / \mathrm{kg} /$ day and continued daily for the total period of experiment (Hassani et al. 2015).

\section{Malathion-treated group (G3)}

Once a day, the mice were administered with malathion dissolved in corn oil at a dose of $27 \mathrm{mg} / \mathrm{kg}$ bw (1/50 of the LD50 for an oral dose) (John et al. 2001) via gavage and continued daily for the total period of experiment.

\section{Curcumin plus malathion-treated group (G4)}

The mice were treated with curcumin and corn oil at a dose of $200 \mathrm{mg} / \mathrm{kg} /$ day once daily, by gavage, and then after half an hour, malathion dissolved in corn oil with a dose of $(27 \mathrm{mg} / \mathrm{kg}$ bw/day) was given by gavage all throughout the experimental period.

\section{Body and reproductive organ weights}

Initial (in the beginning of experiment) and final (by the end of experiment) body weights were recorded. Male mice from all groups were sacrificed after anesthesia by cervical dislocation after 4 weeks of exposure. The testis absolute weights were determined after their extraction and blotting. Gross signs of body and reproductive organs were examined for toxicological parameters. The relative testis weight to body weight was calculated as the ratio of tissue wet weight $(\mathrm{g})$ to body weight $(\mathrm{g})$ (Relative testis weight $=$ testis wet weight/final body weight $\times 100$ ).

\section{Hormone assays}

Serum levels of LH and FSH were measured using automated immunofluorescent assay-based commercial kits and a Brahms Kryptor immunoassay analyzer. Levels of testosterone were measured using a chemiluminescence immunoassay-based commercial kit and an Access immunoassay analyzer.

\section{Plasma acetylcholinesterase activity (AChE)}

Acetylcholinesterase activity was measured using the method of Ellman et al. (1961). The method uses DTNB (5,5-dithio-bis-2-nitrobenzoic acid) to measure the amount of thiocholine produced as acetylthiocholine is hydrolyzed by AChE. The color of DTNB adduct can be measured using spectrophotometry at $412 \mathrm{~nm}$. AChE activity was expressed as micromole sulfhydryl (SH) groups per gram tissue per minute.

\section{Lipid peroxidation (LPO)}

Testicular level of MDA was estimated according to Bulku's technique (Bulku et al. 2012). Briefly, 0.67\% 2-thiobarbituric acid (TBA) and 20\% trichloroacetic acid solution were blended with $0.2 \mathrm{~mL}$ supernatant of testis homogenate and heated for $30 \mathrm{~min}$ in a boiling water bath. The reaction of TBA with MDA formed a pink-colored chromogen, which is estimated spectrophotometrically at $532 \mathrm{~nm}$. The measured outcomes were presented as MDA millimoles per gram tissue.

\section{Testicular superoxide dismutase (SOD) estimation}

Testicular homogenate activity of SOD was estimated according to Masayasu and Hiroshi (1979) technique. This method is based on the production of superoxide anions by pyrogallol autoxidation, detection of produced superoxide anions by nitro blue tetrazolium (NBT) formazan color development, and estimation of the amount of produced superoxide anions scavenged by SOD (the inhibitory level of formazan color development). The spectrophotometer is used to measure the increase in the absorbance for $5 \mathrm{~min}$ at $560 \mathrm{~nm}$. The measured outcomes were presented as units per gram tissue. 


\section{Measurement of testicular CAT activity}

The method of Aebi (1984) was used to determine the testicular catalase (CAT) activity in tissue homogenates. The rate of $\mathrm{H}_{2} \mathrm{O}_{2}$ decomposition was followed by monitoring absorption at $240 \mathrm{~nm}$ in $50 \mathrm{mM}$ phosphate buffer, $\mathrm{pH} 7.0$, containing $10 \mathrm{mM} \mathrm{H}_{2} \mathrm{O}_{2}$. One unit of catalase activity is defined as the amount of enzyme required to decompose $1 \mu \mathrm{mol}$ of hydrogen peroxide in $1 \mathrm{~min}$. The measured outcomes were presented as units per gram tissue.

\section{Measurement of testicular GSH level and GPx activity}

GSH level was estimated according to Beutler et al (1963) technique, and glutathione peroxidase (GPx) level was estimated according to Lawrence and Burk (1976) technique.

\section{Histopathology}

The tissues of the right testis were fixed in Bouin's solution and then processed and embedded in paraffin. Then, paraffin-embedded sections $(5 \mu \mathrm{m})$ were cut, put on slides, and deparaffinized after being rehydrated. The slides were stained with hematoxylin and eosin (HE) to be examined by light microscopy.

\section{Histopathological evaluation}

First, sections were examined by screening and low power to assess adequacy of specimen and take initial impression of overall heterogeneity and assess for tubular diameters, intratubular neoplasia, granulomas, tubular and interstitial fibrosis, or inflammation. Then, sections were examined by high power to assess types and proportions of germ cells.

Hypo-spermatogenesis was defined as the presence of mature sperms in decreased than expected quantities \pm Sertoli cell prominence or increased number of small diameter tubules. In addition, if there are hyalinized tubules or Sertoli cell only, tubules scattered on a background of normal tubules.

\section{Immunohistochemistry}

The sections from the testes were processed as described above but using positively charged slides. Immunohistochemistry was conducted following instructions of $\mathrm{SABC}$ kits. Briefly, slides were treated with $3 \% \mathrm{H}_{2} \mathrm{O}_{2}$ and $5 \%$ BSA blockage for antigen retrieval, then incubated with primary antibodies, caspase 3 and $\mathrm{Bcl}-2$, overnight at $4{ }^{\circ} \mathrm{C}$. Horseradish peroxidase (HRP)-conjugated secondary antibody was used at a 1:700 in blocking solution for $1 \mathrm{~h}$ at 37 ${ }^{\circ} \mathrm{C}$. 3,3-Diaminobenzidine tetrahydrochloride (DAB) was used as chromagen, and hematoxylin (Vector, Houston, TX) was used as a counter stain for the nuclei. Randomly selected ten seminiferous tubules from each slide were examined. Sections were examined by a light microscope on low and high power. Semi-quantitative method was used to assess intensity of stain, which was expressed as mild, moderate, or marked. Distribution of stain among germ cells was also considered. Cytoplasmic staining was considered for both Bcl-2 and Caspase3. The percent areas of immunohistochemical reaction were analyzed using image analyzer computer system (Image J software).

\section{Statistical analysis}

Statistical analysis was done using SPSS software, version 22 for windows (SPSS, Inc., Chicago, IL, USA). Numerical data obtained from the experiment were expressed as mean $\pm \mathrm{SD}$. After ascertaining the homogeneity of variance between treatment groups, one way analysis of variance (ANOVA) followed by Student-Newman-Keuls test was performed. Values of $p<0.05$ were considered to be statistically significant.

\section{Results}

No animal mortalities were found throughout the experimental period.

\section{Effects of malathion and curcumin on body weight gain and testis weights}

As can be seen from Table 1, the relative body weight is significantly decreased in malathion-treated group $(p<0.05)$ and the animals regain their weight gains after the co-administration of curcumin with malathion in group 4, and the body weights become near those of the control group $(p>0.05)$. Relative testis weight is markedly affected in malathion-treated group $(p<0.05)$. This effect significantly improved in group 4 which was treated with curcumin and malathion $(p<0.05)$.

Effects of malathion and curcumin on serum levels of $\mathrm{LH}$, FSH, and testosterone and acetylcholinesterase activity

As can be seen from Table 2, compared with the control and curcumin groups (groups 1 and 2, respectively), serum LH levels, testosterone level, and acetylcholinesterase activity in the malathion-treated group (group 3 ) were significantly lower $(p<0.05)$ and the serum FSH levels were significantly increased $(p<0.05)$. Co-administration of curcumin with malathion in group 4 improves the serum levels of these hormones and enzymes and regains them to near control group levels $(p<0.05)$. Non-significant difference was found in all the parameters between the control group and curcumin with malathion group $(p>0.05)$.

\section{Effects of malathion and curcumin on oxidative stress markers in the testis}

SOD, CAT, and GPx were determined as important endogenous antioxidant enzymes with GSH in the testis. As can be seen from Table 3 and compared with the control and curcumin groups (groups 1 and 2, respectively), the 
Table 1 Changes in body weight and testis weight of mice after 4 weeks of exposure to curcumin (200 mg/kg/day), malathion (27 mg/kg bw), and their combination. $n=12$ mice for each group

\begin{tabular}{lllll}
\hline Parameters & G1 (control) & G2 (curcumin) & G3 (malathion) & G4 (malathion + curcumin) \\
\hline IBW (g) & $25.66 \pm 3.01$ & $26.16 \pm 2.56$ & $27.83 \pm 3.12$ & $27.50 \pm 3.01$ \\
FBW (g) & $31.33 \pm 1.36$ & $31.83 \pm 1.60$ & $26.00 \pm 1.67^{\mathrm{ab}}$ & $32.00 \pm 1.67^{\mathrm{c}}$ \\
RBW & $122.99 \pm 9.62$ & $122.49 \pm 11.37$ & $94.02 \pm 7.83^{\mathrm{ab}}$ & $117.33 \pm 12.29^{\mathrm{c}}$ \\
TW & $0.26 \pm 0.03$ & $0.27 \pm 0.03$ & $0.18 \pm .02^{\mathrm{ab}}$ & $0.27 \pm .02^{\mathrm{c}}$ \\
RTW & $0.81 \pm 0.06$ & $0.84 \pm 0.09$ & $0.69 \pm 0.05^{\mathrm{ab}}$ & $0.85 \pm .06^{\mathrm{c}}$ \\
\hline
\end{tabular}

Data are mean \pm SD. Relative body weight $=$ (final body weight/initial body weight $) \times 100$. Relative testis weight $=($ testis weight/final body weight $) \times 100$ G1 control, G2 curcumin, G3 malathion, G4 malathion + curcumin, IBW initial body weight, $F B W$ final body weight, $T W$ testis weight, $R B W$ relative body weight, $R T W$ relative testis weight

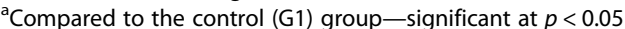

${ }^{b}$ Compared to the curcumin (G2) group-significant at $p<0.05$

${ }^{c}$ Compared to the malathion (G3) group-significant at $p<0.05$

malathion-treated group has MDA levels that were substantially increased $(p<0.05)$, and their SOD, CAT, GPx, and GSH levels were significantly reduced $(p<0.05)$. However, compared to those in the malathion-treated group, there was a significant increase in SOD, CAT, GPx, and GSH level $(p<0.05)$ and decreased level of MDA in group 4 which was treated with curcumin and malathion. Non-significant difference was found in all the parameters between control group and curcumin with malathion group $(p>0.05)$.

\section{Effect of malathion and curcumin on the histological structure of the testis}

Sections examined from cases of control group (Fig. 1a, b) and group treated with curcumin alone (Fig. 1c, d) revealed normal testicular tissue with seminiferous tubules showing full maturation to spermatids and mature spermatozoa in the lumen. Sections from the group treated with malathion (Fig. 2a-c) showed hypospermatogenesis, maturation arrest at stages of primary and secondary spermatocytes focally in $100 \%$ of cases, foci of germ cell aplasia (Sertoli cell only) in about $40 \%$ of cases, sloughing and disorganization, foci of intratubular necrosis and inflammatory infiltrate, interstitial edema and Leydig cell hyperplasia. Sections from the group treated by both malathion and curcumin (Fig. 3a, b) showed normal spermatogenesis in $50 \%$ of cases, mixed hypospermatogenesis and maturation arrest in 50\% of cases, no germ cell aplasia, sloughing and disorganization (50\%), no necrosis or inflammatory infiltrate, mild interstitial edema in $25 \%$ of cases, and no Leydig cell hyperplasia.

\section{Immunohistochemistry}

Bcl-2 was expressed in the testis of mice from all groups but with different intensity and distribution. In the control, curcumin, and malathion + curcumin groups, there was moderate cytoplasmic Bcl-2 expression. Expression was prominent mainly in spermatocytes and spermatids. Leydig cells also showed some immunoreactivity. Bcl-2 expression was weak in the malathion-treated group. There was no expression in spermatogonia (Fig. 4). As regards percent area of expression of Bcl-2 immunoreaction of the testis, a statistically significant difference was observed between malathion-treated group and both control and curcumin groups $(p<0.05)$. There was a statistically significant difference in the expression of $\mathrm{Bcl}-2$ immunoreaction in the malathion + curcumin group compared with the malathion group $(p<0.05)$ as presented in Table 4.

Caspase3 was moderately expressed in the testis of mice from all groups. The expression was mainly cytoplasmic. It presents in all cells from spermatogonia to spermatids. There was no difference in expression among groups (Fig. 5). As regards percent area of expression of Caspase3 immunoreaction of the testis, no

Table 2 Changes in serum levels of LH, FSH, testosterone, and acetylcholinesterase of mice after 4 weeks of exposure to curcumin (200 mg/kg/day), malathion (27 mg/kg bw), and their combination. $n=12$ mice for each group

\begin{tabular}{lllll}
\hline Parameters & G1 (control) & G2 (curcumin) & G3 (malathion) & G4 (malathion + curcumin) \\
\hline LH $(\mathrm{mll} / \mathrm{mL})$ & $2.85 \pm 0.05$ & $2.90 \pm 0.08$ & $1.38 \pm 0.07^{\mathrm{ab}}$ & $2.71 \pm 0.07^{\mathrm{c}}$ \\
FSH $(\mathrm{mlU} / \mathrm{mL})$ & $2.76 \pm 0.05$ & $2.78 \pm 0.04$ & $5.31 \pm 0.31^{\mathrm{ab}}$ & $2.89 \pm 0.05^{\mathrm{c}}$ \\
TS $(\mathrm{ng} / \mathrm{ml})$ & $2.90 \pm 0.11$ & $2.98 \pm 0.15$ & $1.87 \pm 0.10^{\mathrm{ab}}$ & $2.80 \pm 0.09^{\mathrm{c}}$ \\
Ache $(\mu \mathrm{mol} \mathrm{SH} / \mathrm{g} / \mathrm{min})$ & $7.03 \pm 0.16$ & $7.02 \pm 0.23$ & $4.78 \pm 0.15^{\mathrm{ab}}$ & $6.87 \pm 0.12^{c}$ \\
\hline
\end{tabular}

Data are mean \pm SD

G1 control, G2 curcumin, G3 malathion, G4 malathion + curcumin, LH luteinizing hormone, FSH follicle-stimulating hormone, TS testosterone,

Ache acetylcholinesterase

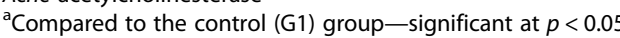

${ }^{\mathrm{b}}$ Compared to curcumin (G2) group-significant at $p<0.05$

${ }^{\mathrm{C} C o m p a r e d ~ t o ~ m a l a t h i o n ~(G 3) ~ g r o u p-s i g n i f i c a n t ~ a t ~} p<0.05$ 
Table 3 Changes in oxidative stress markers in the testis of mice after 4 weeks of exposure to curcumin (200 mg/kg/day), malathion (27 mg/kg bw), and their combination. $n=12$ mice for each group

\begin{tabular}{lllll}
\hline Parameters & G1 (control) & G2 (curcumin) & G3 (malathion) & G4 (malathion + curcumin) \\
\hline CAT (U/g tissue) & $347.50 \pm 17.78$ & $348.33 \pm 19.28$ & $216.33 \pm 12.72^{\mathrm{ab}}$ & $318.00 \pm 19.39^{\mathrm{c}}$ \\
SOD (U/g tissue) & $293.33 \pm 6.02$ & $298.83 \pm 7.36$ & $227.33 \pm 11.09^{\mathrm{ab}}$ & $281.83 \pm 9.70^{\mathrm{c}}$ \\
GSH (mmol/gm tissue) & $45.18 \pm 3.42$ & $47.56 \pm 4.22$ & $30.78 \pm 2.62^{\mathrm{ab}}$ & $46.48 \pm 2.38^{\mathrm{c}}$ \\
GPx (mmol/gm tissue) & $6.68 \pm 0.32$ & $6.78 \pm 0.42$ & $4.36 \pm 0.24^{\mathrm{ab}}$ & $5.98 \pm 0.28^{\mathrm{c}}$ \\
MDA (mmol/g tissue) & $41.67 \pm 3.39$ & $44.33 \pm 3.08$ & $86.66 \pm 4.03^{\mathrm{ab}}$ & $49.66 \pm 3.44^{\mathrm{c}}$ \\
\hline
\end{tabular}

Data are mean \pm SD

G1 control, G2 curcumin, G3 malathion, G4 malathion + curcumin, CAT catalase, SOD superoxide dismutase, GSH glutathione, GPx glutathione peroxidase, MDA malondialdehyde

${ }^{a}$ Compared to the control (G1) group-significant at $p<0.05$

${ }^{\mathrm{b}}$ Compared to curcumin (G2) group-significant at $p<0.05$

${ }^{c}$ Compared to malathion (G3) group—significant at $p<0.05$

statistically significant difference was observed among groups $(p>0.05)$ as presented in Table 4.

\section{Discussion}

Insecticides have been widely used for decades, and human exposure to these insecticides always causes public health concern. Malathion is an organophosphate insecticide widely used in agriculture, residential areas, public recreation areas, and pest control programs, and it is also used for the treatment of the head and body lice (Stone et al. 2014). The compounds of organophosphorus are broadly utilized as acaricides and insecticides in agriculture. They are likewise often utilized in drug and industry. Residues of organophosphate (OP) insecticides have been recognized in the food products, grains, vegetables, water bodies, and soil (Poet et al. 2004). In addition, because of the extensive accessibility of organophosphorus pesticides, toxicity is widespread

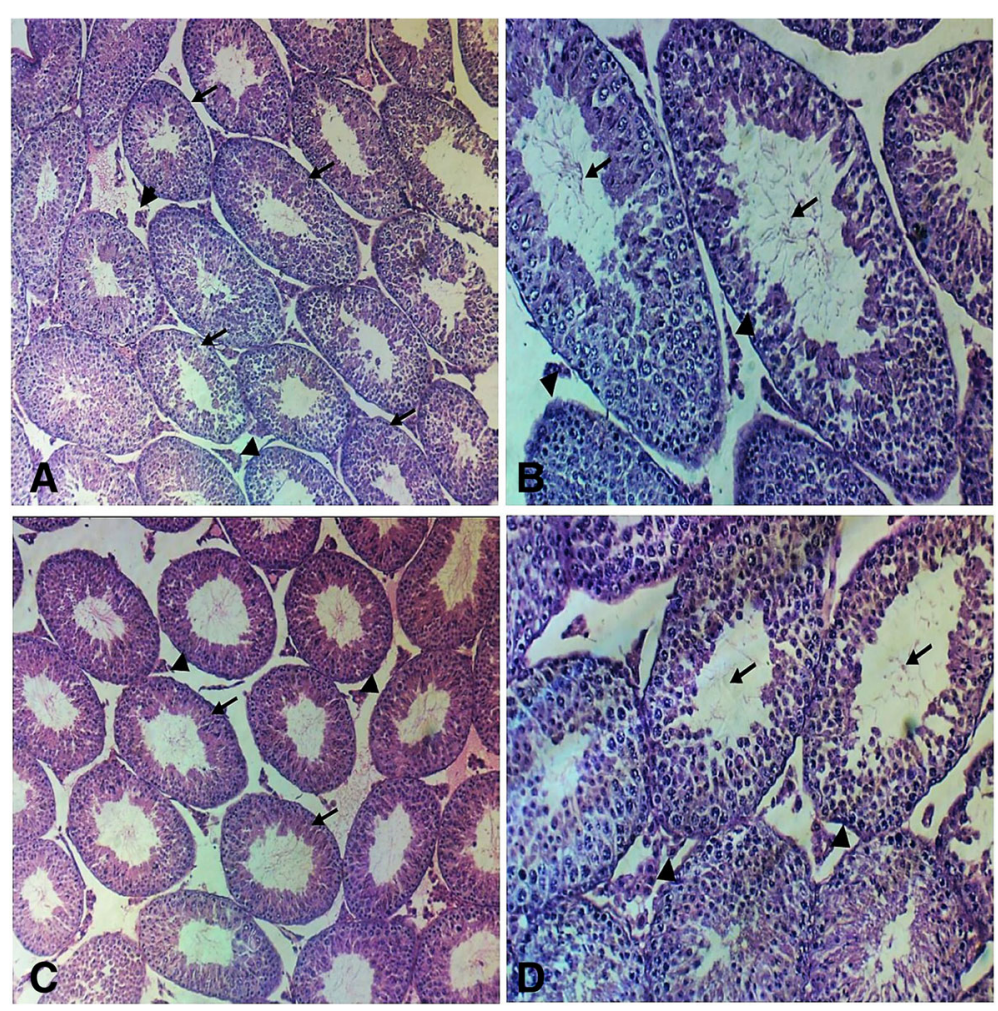

Fig. 1 Photomicrograph of the testis section stained with hematoxylin and eosin from the control and curcumin groups under the study. $\mathbf{a}, \mathbf{b}$ (control group) showing a uniform seminiferous tubules (black arrows), with small clusters of Leydig cells in interstitial tissue (arrow heads) (H\&E, $\times 10$ ) and $\mathbf{b}$ uniform spermatogenesis, with identification of sperm in tubular lumens tubules (black arrows), with small clusters of Leydig cells in interstitial tissue (arrow heads) (H\&E, $\times 20)$. c, d (curcumin group); c uniform seminiferous tubules (black arrows), with small clusters of Leydig cells in interstitial tissue (arrow heads) (H\&E, $\times 10)$ and $\mathbf{d}$ uniform spermatogenesis, with identification of sperm in tubular lumens tubules (black arrows), with small clusters of Leydig cells in interstitial tissue (arrow heads) $(H \& E, \times 20)$ 


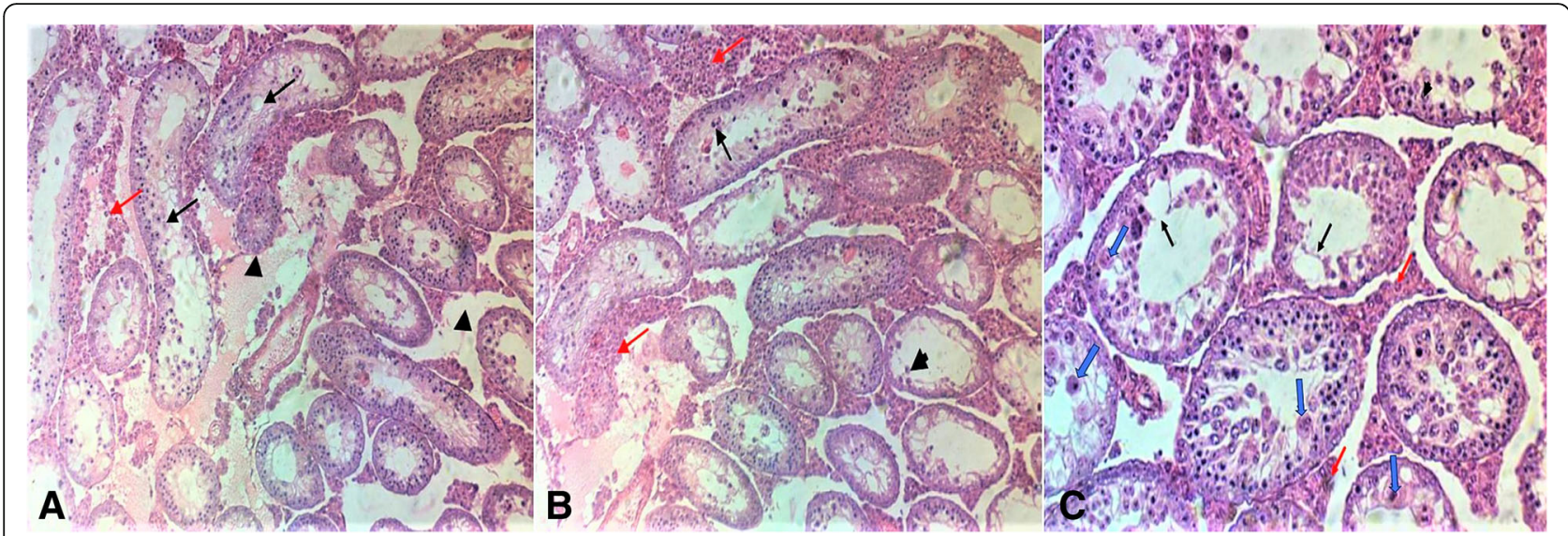

Fig. 2 Photomicrograph of the testis section stained with hematoxylin and eosin from the malathion group under the study. a-c showing a seminiferous tubules become irregular in shape and show disrupted sloughed lining (black arrows), with widened edematous hemorrhagic interstitial tissue (arrow heads). There are foci of Leydig cell hyperplasia (red arrow) (H\&E, $\times 10)$. b Spermatogenic cells show maturation arrest with no identifiable sperm in the lumens. There are sloughed swollen cells in the lumens (black arrows). There are foci of Leydig cell hyperplasia (red arrows). Some tubules show only Sertoli cell lining (arrow head) $(H \& E, \times 20)$. c Seminiferous tubules show disturbed sloughed lining (black arrows), with late maturation arrest. No sperm is seen in lumens. Many degenerated swollen sloughed spermatogenic cells are seen (blue arrows). Some tubules show few neutrophilic infiltrate within lining cells (arrow heads). Leydig cells show hyperplasia (red arrows) $(H \& E, \times 20)$

(Garcia et al. 2003). Previous researches have reported that the male reproductive system have been affected by some OP insecticides (Farag et al. 2000). Malathion is an organophosphorus insecticide that affects the reproductive system. Humans, birds, and other animals are in contact to increased levels of this insecticide (malathion), due to its common utilization and the rising rates of food contamination (Babu et al. 2006).

In this study, we introduced malathion at a dose of 1/ 50 of the oral LD50 and observed the pathological changes in mice testes. None of the mice died during the interval of experiment.

Malathion caused changes in the mouse testis, notably by a decrease in their weight. The same finding was demonstrated in a research done by Geng et al. and Slimen et al. (2014; 2015). The reported data presented by Lafuente et al. (2008) dedicated that oral exposure to malathion caused adverse effects on the reproductive system of male mice following intake of $27 \mathrm{mg} / \mathrm{kg}$ per day for 1 month, including lowered weight of the body and testes.

LH and FSH activities depend on both the quantity of these hormones and availability of their specific receptors in the testis. It was clarified that there is an adverse effect on testicular function on exposure to environmental pollutants mediated by lowering LH secretion by pituitary and steroidogenesis by Leydig cell (Geng et al. 2015; Magnusson and Ljungvall 2014). By the end of the month of this study, the levels of LH and testosterone in the group treated by malathion were significantly lower than their levels in mice in the group taken as control and the FSH is higher in the malathion-treated group.

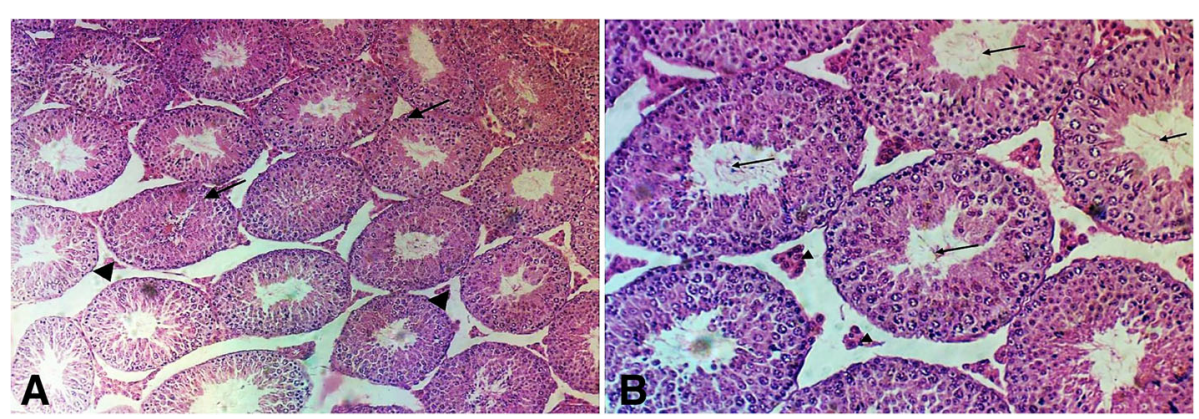

Fig. 3 Photomicrograph of the testis section stained with hematoxylin and eosin from the malathion + curcumin group under the study. $\mathbf{a}, \mathbf{b}$ showing a uniform seminiferous tubules (black arrows), with small clusters of Leydig cells in interstitial tissue (arrow heads) (H\&E, $\times 10)$. b Uniform regular seminiferous tubules with uniform full spermatogenesis, with identification of sperm in tubular lumens tubules (black arrows), with significant reduction in number of Leydig cells in interstitial tissue (arrow heads) (H\&E, $\times 20$ ) 


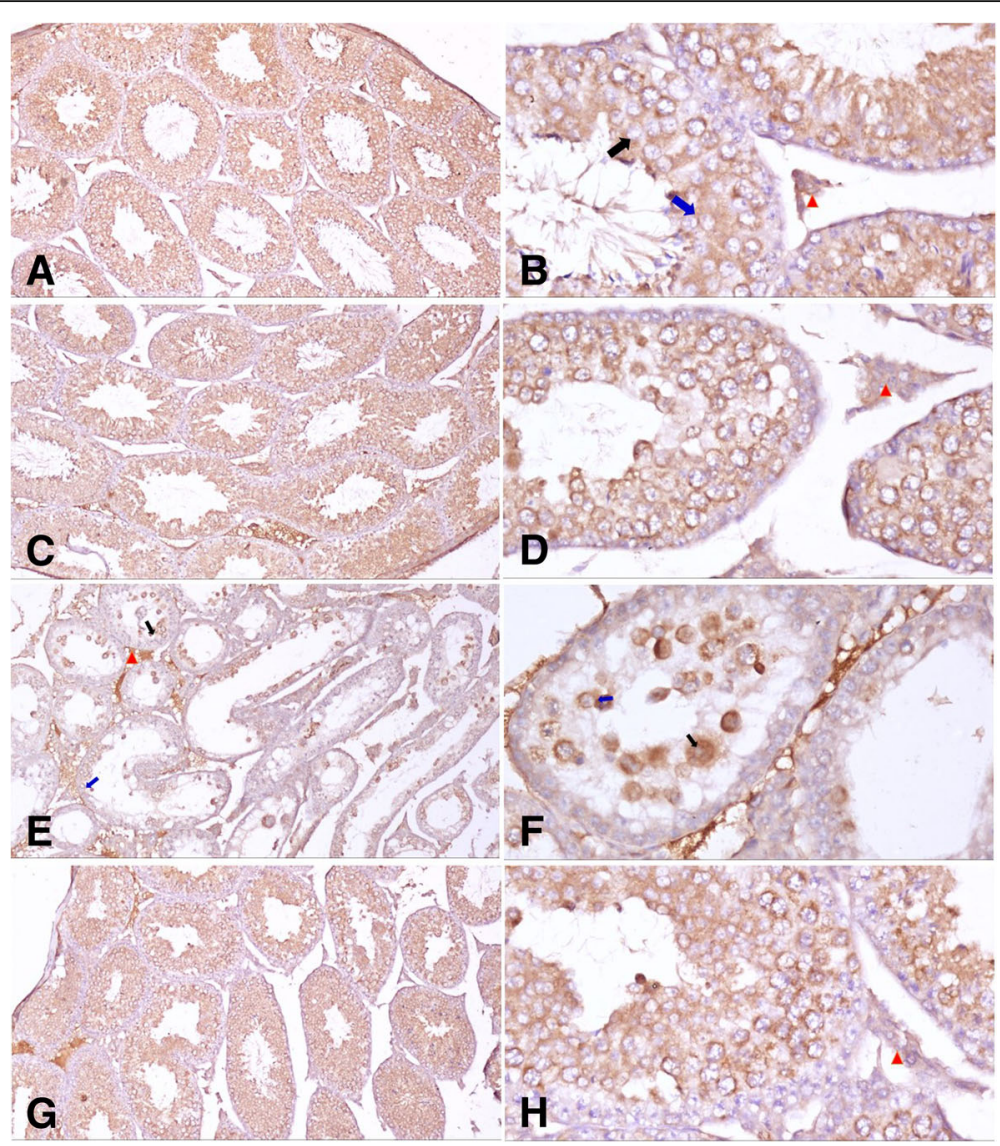

Fig. 4 Photomicrographs of a cytoplasmic Bcl-2 expression in the testis of mice showing moderate immunoreactivity in control group. $\mathbf{b}$ Cytoplasmic BCl-2 expression in the testis of mice showing moderate immunoreactivity in control group. Expression is prominent mainly in spermatocytes (black arrows) and spermatids (blue arrows). Leydig cells (red arrowheads) also show some immune reactivity. c Cytoplasmic Bcl-2 expression in the testis of mice showing moderate immunoreactivity in seminiferous tubules of curcumin-treated group. $\mathbf{d}$ Cytoplasmic Bcl-2 expression in the testis of mice showing moderate immunoreactivity in seminiferous tubules of curcumin-treated group. Leydig cells (red arrowheads) also show some immune reactivity. e Cytoplasmic Bcl-2 expression in the testis of mice showing weak immunoreactivity in the malathion-treated group. Expression is prominent mainly in spermatocytes (black arrows) and spermatids (blue arrows). Leydig cells (red arrowheads) also show some immune reactivity. $\mathbf{f}$ Cytoplasmic $\mathrm{Bcl}-2$ expression in the testis of mice showing weak immunoreactivity in the malathion-treated group. Expression is prominent mainly in spermatocytes (black arrows) and spermatids (blue arrows). $\mathbf{g}$ Cytoplasmic Bcl-2 expression in the testis of mice showing moderate immunoreactivity in seminiferous tubules of the curcumin + malathion-treated group. $\mathbf{h}$ Cytoplasmic Bcl-2 expression in the testis of mice showing moderate immunoreactivity in seminiferous tubules of the curcumin + malathiontreated group. Leydig cells (red arrowheads) also show some immune reactivity. Photomicrographs of $\mathbf{a}, \mathbf{c}, \mathbf{e}$, and $\mathbf{g}$ are at $\times 100$ resolution by immunohistochemistry staining using anti-Bcl-2 monoclonal antibody with hematoxylin counterstain. Photomicrographs of $\mathbf{b}, \mathbf{d}, \mathbf{f}$, and $\mathbf{h}$ are at $\times 400$ resolution by immunohistochemistry staining using anti-BCl-2 monoclonal antibody with hematoxylin counterstain

Table 4 Percent area (\%) stained by $\mathrm{Bcl}-2$ and Caspase3 immunoreaction of the testis in mice after 4 weeks of exposure to curcumin $(200 \mathrm{mg} / \mathrm{kg} / \mathrm{day})$, malathion $(27 \mathrm{mg} / \mathrm{kg} \mathrm{bw})$, and their combination. $n=12$ mice for each group

\begin{tabular}{lllll}
\hline Parameters & G1 (control) & G2 (curcumin) & G3 (malathion) & G4 (malathion + curcumin) \\
\hline Bcl-2 & $45.148 \pm 3.02$ & $42.366 \pm 5.55$ & $17.259 \pm 2.67^{\text {ab }}$ & $43.714 \pm 2.83^{c}$ \\
Caspase3 & $34.416 \pm 3.79$ & $35.620 \pm 3.65$ & $34.914 \pm 2.03$ & $34.485 \pm 3.72$ \\
\hline
\end{tabular}

\footnotetext{
Data are mean \pm SD
}

G1 control, G2 curcumin, G3 malathion, G4 malathion + curcumin

${ }^{a}$ Compared to the control (G1) group-significant at $p<0.05$

${ }^{\mathrm{b}}$ Compared to curcumin (G2) group-significant at $p<0.05$

'Compared to malathion (G3) group-significant at $p<0.05$ 


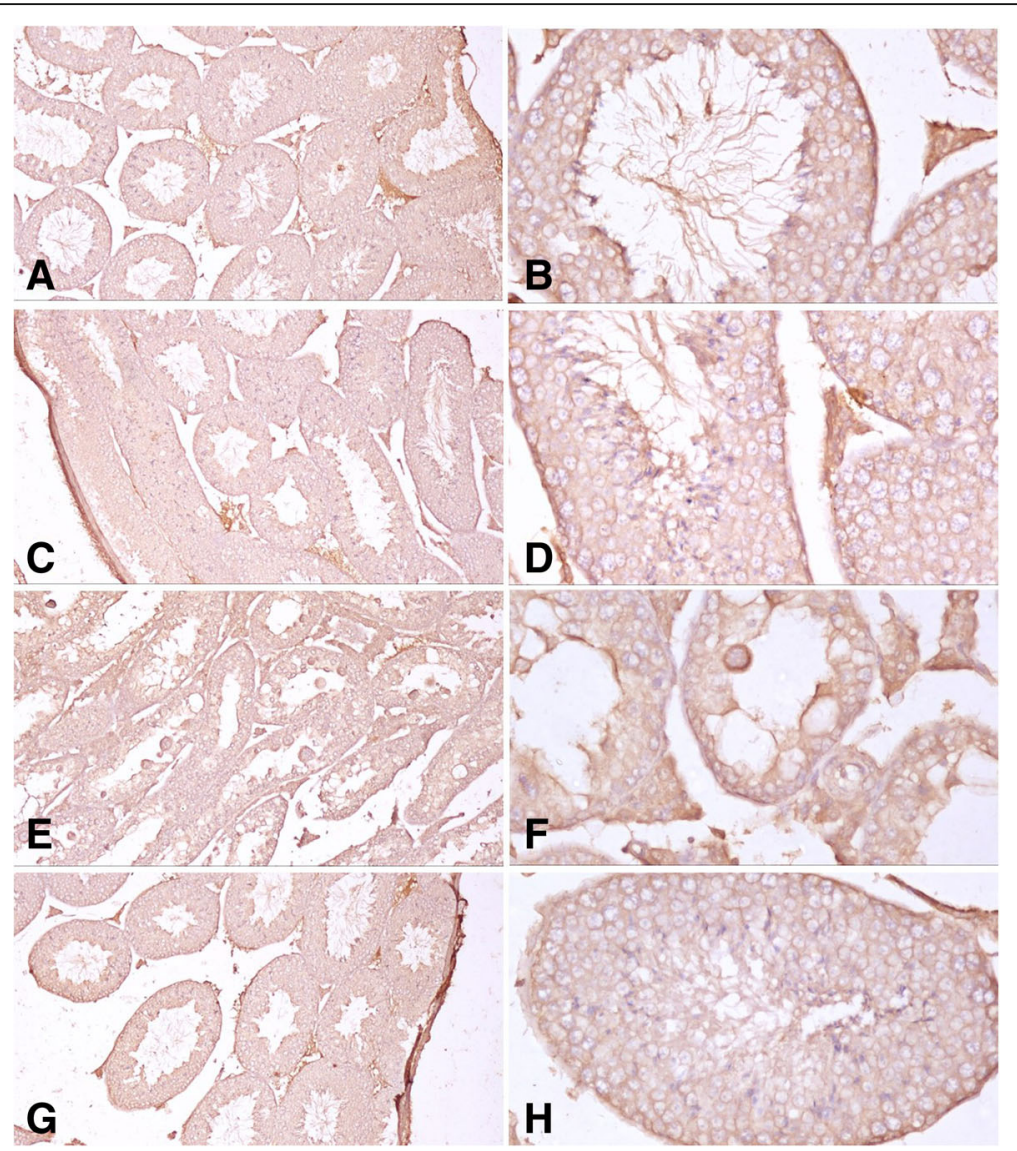

Fig. 5 Photomicrographs of $\mathbf{a}, \mathbf{b}$ control group: normal seminiferous tubules showing moderate immunoreactivity for caspase 3 detected as cytoplasmic staining in all types of cells. $\mathbf{c}$, $\mathbf{d}$ Curcumin-treated group: normally functioning seminiferous tubules showing moderate immunoreactivity for caspase 3 detected as cytoplasmic staining in all types of cells. e, $\mathbf{f}$ Malathion-treated group showing moderate immunoreactivity for caspase 3 detected as cytoplasmic staining in all types of cells. Note the more intense stain in the cytoplasm of enlarged degenerating spermatocytes. $\mathbf{g}$, $\mathbf{h}$ Curcumin + malathion-treated group: seminiferous tubules showing moderate immunoreactivity for caspase 3 detected as cytoplasmic staining in all types of cells. Photomicrographs of $\mathbf{a}, \mathbf{c}, \mathbf{e}$, and $\mathbf{g}$ are at $\times 100$ magnification by immunohistochemistry staining using anti-caspase 3 monoclonal antibody with hematoxylin counterstain. Photomicrographs of $\mathbf{b}, \mathbf{d}, \mathbf{f}$, and $\mathbf{h}$ are at $\times 400$ magnification by immunohistochemistry staining using anti-caspase 3 monoclonal antibody with hematoxylin counterstain

Thus, malathion administration suppressed $\mathrm{LH}$ and testosterone release and increased the level of FSH. This is in line with the finding of Mahgoub and El-Medany (2001) who found elevated FSH in the insecticide-treated group. However, decreased levels of $\mathrm{LH}, \mathrm{FSH}$, and testosterone have been reported by other authors (Maitra and Mitra 2008; Elbetieha and Da'as 2003). This may be made clear by the supposed antagonism of malathion to androgen receptor. It is known that antagonists to androgen receptor can change the glycosylation of gonadotrophins, and this leads to the inhibition of their levels (Sikka and Naz 1999). Some researchers considered a change in the mechanism of production of steroid hormones. It is probable that production of gonadotropins was affected by malathion in male mice due to the interruption of the hypothalamic-pituitary-testicular axis (Roohbakhsh et al. 2011).
Gonadotrophins and testosterone are key hormones, which regulate spermatogenesis. $\mathrm{LH}$ is secreted by the pituitary gland then induces Leydig cells to secrete testosterone. Many OPs were tested for their effect on plasma levels of testosterone (Blanco-Muñoz et al. 2010; Satar et al. 2004). In our experiment, introducing malathion for 4 weeks was associated with a reduction in plasma levels of testosterone. There may be pathological alterations in the interstitial cells of Leydig, which may be the reason for that effect. However, levels of plasma testosterone showed no significant effect under organophosphorus insecticide exposure as mentioned by Okamura et al. (2005). Some researchers described the adverse effect of malathion on the fertility through its reduction effect on levels of plasma testosterone (Contreras and Bustos-Obregón 1999). Studies have shown that many organophosphate pesticides including malathion can interfere with hormone levels through 
activating estrogen, androgen, and other hormone receptors (McKinlay et al. 2008; Mnif et al. 2011).

The current study depicted the low level of acetylcholinesterase in malathion-treated group. These results are similar to the previous researchers who stated that pseudocholinesterase and acetylcholinesterase activity have been inhibited by the organophosphorus pesticides in the body tissues (John et al. 2001; Kalender et al. 2006; Rubin et al. 2002). These changes depend on concentration and intensify with longer exposure. The effects of malathion and other OPs may be at least partially because of they are able to cross the bloodtestis barrier and enhance oxidative stress and peroxidation of lipids causing damage to the testes (Uzunhisarcikli et al. 2007). Malathion does not directly inhibit action of the acetylcholinesterase before it is biotransformed. The toxicity to mammals of organophosphorus pesticides as malathion depends on mixed function oxidase (MFO) induced activation to its analogous oxygen correspondent, which directly inhibit acetylcholinesterase (Pope 1999). Therefore, biological effects of malathion can be due to electrophilic attack on the cells with concomitant production of reactive oxygen species (Johnson et al. 2000). Therefore, the harmful effects of malathion on reproductive system of male mice may be due to its electrophilic attack on their cells.

Erythrocyte membranes damage through a mechanism of oxidative stress had been reported in previous researches after malathion administration orally for more than 6 weeks at a dose of $0.13 \mathrm{mg} / \mathrm{kg}$ (John et al. 2001). In addition, alterations in CAT and SOD activity in the different regions of the brain and oxidative damage had been induced by malathion exposure (Fortunato et al. 2006a, b). Our results clearly verified other researches, which told that giving organophosphorus insecticides to male mice changed the activity of antioxidant enzymes in tissues of reproductive organs in the form of decreased GSH level with suppressed SOD, CAT, and GPx activity.

A major underlying mechanism of OP toxicity is oxidative stress that results from the generation of many free radicals, and correspondent depletion of antioxidant enzymes. The results are oxidation of DNA, protein, and lipids (Koltuksuz et al. 2000). Moreover, OPs themselves can directly attack cellular membranes and form lipid peroxidation products or enter the cytoplasm and generate free oxygen radicals. The result is increased oxidative stress, leading to a more depletion of antioxidant enzymes in the cell and disruption of the oxidant-antioxidant scale favoring the oxidant limb (Pearson and Patel 2016).

Insecticides can cause variable histopathological and cytopathological lesions in the testes of male mice (Mahgoub and El-Medany 2001; Uzunhisarcikli et al.
2007). These changes include defective spermatogenesis (Farag et al. 2000; Khan et al. 2001; Uzunhisarcikli et al. 2007).

The organophosphorus insecticides including malathion may lead to degeneration of the germ and Leydig cells. This disrupts spermatogenesis and reduces sperm numbers (Uzunhisarcikli et al. 2007). This coincides with our results that showed marked hypospermatogenesis and even germ cell aplasia in the group treated by malathion.

Uzun et al. (2009) declared malathion-caused necrosis in the seminiferous tubules and edema in interstitial tissue. This agrees with our results. The same researchers also mentioned that destruction of DNA, proteins, and lipids through a mechanism of oxidative stress had been promoted by the deleterious effects of OPs (malathion) within the testis. This same happened when curcumin was used in our experiment to reduce the oxidative injuries. Oldereid et al. (2001) stated also that the spermatogenic inhibition induced by cisplatin may be due to the formation of free radicals in the testicular tissue. Spermatogenesis improved among curcumin-treated mice. This may be associated with the antioxidant and free radical scavenger properties of the curcumin. This coincides with our hypothesis about curcumin.

Oldereid et al. (2001) had reported that all male germ cell levels in humans may undergo spontaneous apoptosis. Bcl-2 family proteins have been suggested to play a particular role in the process of maturation and differentiation occurs in spermatogenesis of human, as they have been found to be distributed within distinguished germ cell levels. In the current study, expression was more prominent in spermatocytes and spermatids. However, Tanaka et al. (2002) showed that Bcl-2, BAX, caspase1, and caspase 3 are expressed in germ cells of the human testes, especially in basal cells such as spermatogonia, with expression only rarely in spermatids.

Previous studies have reported that utilization of caspase3 apoptosis played a vital role in the process of human testicular spermatogenesis, and the increase in apoptosis has been mentioned to happen in the process of hypospermatogenesis, maturation arrest, and syndrome of Sertoli cell only (Almeida et al. 2013).

Geng et al. (2015) concluded that malathion effects on the testicular spermatogenic function of male rats and its working mechanism may involve cell apoptosis induced by the downregulation of Bcl-2 and upregulation of Bax. This coincides with our results that showed weak Bcl-2 in the group that was exposed to malathion. This was mentioned previously by Khorsandi et al. (2013) in their study.

Our research clarified that curcumin administration minimized malathion-induced testicular toxicity. Therefore, we can assume that curcumin could protect against 
oxidative stress caused by free radical. It does so by scavenging free radicals and minimizing lipid peroxidation and decreasing antioxidant consumption. Majority of antioxidants have either a functional phenolic or a $\beta$-diketone group. Curcumin has several functional groups, including the $\beta$-diketone group, carbon-carbon double bonds, and phenyl rings having variable content of methoxy and hydroxyl substituents (Priyadarsini et al. 2003; Wright 2002). However, curcumin was said to be incapable to prevent MDA production (Reyes-Gordillo et al. 2007). After absorption from the intestine, curcumin is bio-transformed to dihydrocurcumin, tetrahydrocurcumin, and hexahydrocurcumin. These compounds are conjugated to glucuronide, and then, they are more polar and better absorbed than curcumin. Therefore, the pharmacological actions of curcumin are largely induced by curcumin's hydro soluble metabolites (Maheshwari et al. 2006). The methoxy and phenolic groups on benzene rings of curcumin are vital structures which contribute to antioxidant capabilities of curcumin (Samuhasaneeto et al. 2009).

Curcumin has been popular in the past 20 years due to its multiple biological and pharmacological effects, which can modify multiple cell-signaling pathways. Its action is mediated by direct or indirect interaction with multiple molecular targets (Aggarwal and Sung 2009). Its metabolites, curcumin glucuronide (COG) and curcumin sulfate (COS), may retain some of the pharmacological activities of curcumin and responsible for its biological effects (Prasad et al. 2014).

Our finding that giving curcumin to malathion-exposed mice mollified the toxic effects of malathion on the testis supports the idea that malathion causes their harmful effects by causing destructive oxidation of lipids, proteins, and DNA of testicular tissue.

\section{Conclusion}

This study showed that curcumin ameliorates malathion-induced testicular damage. The curcumin effect is mediated through the enhancement of antioxidant enzymes and suppression of oxidative stress markers. Other in vitro studies are needed to define the pathways involved in curcumin actions while competing malathion-induced testicular damage.

\section{Abbreviations}

AChE: Acetylcholinesterase; CAT: Catalase; FSH: Follicle-stimulating hormone; GPx: Glutathione peroxidase; GSH: Glutathione; LH: Luteinizing hormone; LPO: Lipid peroxidation; MDA: Malondialdehyde; OP: Organophosphorus; SOD: Superoxide dismutase

\section{Acknowledgements}

The author would also like to thanks the Department of Pathology, College of Medicine, Saudi Digital Library and University Library providing the facility for literature survey and collection.

\section{Funding}

The authors would like to acknowledge financial support for this work, from the Deanship of Scientific Research, Jouf University, Aljouf, Saudi Arabia, under the no. (420/37).

\section{Availability of data and materials}

Data sharing not applicable to this article as no datasets were generated or analyzed during the current study.

\section{Authors' contributions}

The authors make substantial contributions to conception and design, acquisition of data, analysis, and interpretation of data; the authors participate in drafting the article and revising it critically for important intellectual content; and the authors give final approval of the version to be submitted.

\section{Ethics approval and consent to participate}

All mice were treated in correspondence with the standard guide of the National Institutes of Health guide for the care and use of Laboratory animals and the approved guidelines of the "Jouf ethical committee of Experiments on Animals."

\section{Consent for publication}

Not applicable.

\section{Competing interests}

The authors declare that they have no competing interests.

\section{Publisher's Note}

Springer Nature remains neutral with regard to jurisdictional claims in published maps and institutional affiliations.

\section{Author details}

1Pathology Department, College of Medicine, Jouf University, P.O box.2014, Aljouf Postal Code: 42421, Saudi Arabia. ${ }^{2}$ Pathology Department, Faculty of Medicine, Suez Canal University (SCU), Ismailia Postal Code: 41522, Egypt

${ }^{3}$ Forensic Medicine and Clinical Toxicology Department, College of Medicine, Jouf University, P.O box.2014, Aljouf Postal Code: 42421, Saudi Arabia.

${ }^{4}$ Forensic Medicine and Clinical Toxicology Department, Faculty of Medicine, Suez Canal University (SCU), Ismailia Postal Code: 41522, Egypt.

Received: 29 August 2018 Accepted: 27 November 2018

Published online: 13 December 2018

References

Aebi H (1984) [13] Catalase in vitro. Methods Enzymol 105:121-126.

Aggarwal BB, Sung B (2009) Pharmacological basis for the role of curcumin in chronic diseases: an age-old spice with modern targets. Trends Pharmacol Sci 30(2):85-94

Ak T, Gülçin I (2008) Antioxidant and radical scavenging properties of curcumin. Chem Biol Interact 174(1):27-37.

Almeida C, Correia S, Rocha E, Alves Â, Ferraz L, Silva J, Sousa M, Barros A (2013) Caspase signalling pathways in human spermatogenesis. J Assist Reprod Genet 30(4):487-495.

Babu NS, Malik JK, Rao GS, Aggarwal M, Ranganathan V (2006) Effects of subchronic malathion exposure on the pharmacokinetic disposition of pefloxacin. Environ Toxicol Pharmacol 22(2):167-171.

Bajgar J (2005) Complex view on poisoning with nerve agents and organophosphates. ACTA MEDICA-HRADEC KRALOVE 48(1):3.

Bayrami M, Hashemi T, Malekirad AA, Ashayeri H, Faraji F, Abdollahi M (2012) Electroencephalogram, cognitive state, psychological disorders, clinical symptom, and oxidative stress in horticulture farmers exposed to organophosphate pesticides. Toxicol Ind Health 28(1):90-96.

Beutler E, Duron O, Mikus Kelly B (1963) Improved method for the determination of blood glutathione. J Lab Clin Med 61:882-888.

Blanco-Muñoz J, Morales MM, Lacasaña M, Aguilar-Garduño C, Bassol S, Cebrián ME (2010) Exposure to organophosphate pesticides and male hormone profile in floriculturist of the state of Morelos, Mexico. Hum Reprod 25(7): 1787-1795.

Bulku E, J Stohs S, Cicero L, Brooks T, Halley H, D Ray S (2012) Curcumin exposure modulates multiple pro-apoptotic and anti-apoptotic signaling pathways to antagonize acetaminophen-induced toxicity. Curr Neurovasc Res 9(1):58-71. 
Bustos-Obregón E, González-Hormazabal P (2003) Effect of a single dose of malathion on spermatogenesis in mice. Asian journal of andrology 5(2):105-107.

Contreras HR, Bustos-Obregón E (1999) Morphological alterations in mouse testis by a single dose of malathion. J Exp Zool A Ecol Genet Physiol 284(3):355-359.

Deters M, Siegers C, Hänsel W, Schneider K-P, Hennighausen G (2000) Influence of curcumin on cyclosporin-induced reduction of biliary bilirubin and cholesterol excretion and on biliary excretion of cyclosporin and its metabolites. Planta Med 66(05):429-434.

dos Santos AA, dos Santos DB, Ribeiro RP, Colle D, Peres KC, Hermes J, Barbosa AM, Dafré AL, de Bem AF, Kuca K (2011) Effects of K074 and pralidoxime on antioxidant and acetylcholinesterase response in malathion-poisoned mice. Neurotoxicology 32(6):888-895.

Elbetieha A, Da'as SI (2003) Assessment of antifertility activities of abamectin pesticide in male rats. Ecotoxicol Environ Saf 55(3):307-313.

Ellman GL, Diane Courtney K, Andres V, Featherstone RM (1961) A new and rapid colorimetric determination of acetylcholinesterase activity. Biochem Pharmacol 7(2):88|N191-88|9095.

Farag AT, Eweidah MH, El-Okazy AM (2000) Reproductive toxicology of acephate in male mice. Reprod Toxicol 14(5):457-462.

Fortunato JÉJ, Agostinho FR, RÉus GZ, Petronilho FíC, Dal-Pizzol F, Quevedo JÃ (2006a) Lipid peroxidative damage on malathion exposure in rats. Neurotox Res 9(1):23-28

Fortunato JJ, Feier G, Vitali AM, Petronilho FC, Dal-Pizzol F, Quevedo J (2006b) Malathion-induced oxidative stress in rat brain regions. Neurochem Res 31(5): 671-678.

Gall Troselj K, Kujundzic RN (2014) Curcumin in combined cancer therapy. Curr Pharm Des 20(42):6682-6696.

Garcia S, Abu-Qare A, Meeker-O'Connell W, Borton A, Abou-Donia M (2003) Methyl parathion: a review of health effects. J Toxicol Environ Health Part B: Crit Rev 6(2):185-210.

Geng X, Shao H, Zhang Z, Ng JC, Peng C (2015) Malathion-induced testicular toxicity is associated with spermatogenic apoptosis and alterations in testicular enzymes and hormone levels in male Wistar rats. Environ Toxicol Pharmacol 39(2):659-667.

Gupta SC, Patchva S, Koh W, Aggarwal BB (2012) Discovery of curcumin, a component of golden spice, and its miraculous biological activities. Clin Exp Pharmacol Physiol 39(3):283-299.

Hassani S, Sepand MR, Jafari A, Jaafari J, Rezaee R, Zeinali M, Tavakoli F, RazaviAzarkhiavi K (2015) Protective effects of curcumin and vitamin E against chlorpyrifos-induced lung oxidative damage. Hum Exp Toxicol 34(6):668-676.

Huang Y, Cao S, Zhang Q, Zhang H, Fan Y, Qiu F, Kang N (2018) Biological and pharmacological effects of hexahydrocurcumin, a metabolite of curcumin. Arch Biochem Biophys 646:31-37.

Ibrahim MA, El Masry MK, Moustafa AA, Hagras AM, Ali NM (2011) Comparison of the accuracy of two scoring systems in predicting the outcome of organophosphate intoxicated patients admitted to intensive care unit (ICU). Egypt J Forensic Sci 1(1):41-47.

Ibrahim M, Almaeen A, El Moneim M, Tammam H, Khalifa A, Nasibe M (2018) Cadmium-induced hematological, renal, and hepatic toxicity: the amelioration by spirulina platensis. Saudi J Forensic Med Sci 1(1):5-13. https://doi.org/10.4103/sjfms.sjfms_7_17..

John S, Kale M, Rathore N, Bhatnagar D (2001) Protective effect of vitamin E in dimethoate and malathion induced oxidative stress in rat erythrocytes. J Nutr Biochem 12(9):500-504.

Johnson MK, Jacobsen D, Meredith TJ, Eyer P, Heath AJ, Ligtenstein DA, Marrs TC, Szinicz L, Vale JA, Haines JA (2000) Evaluation of antidotes for poisoning by organophosphorus pesticides. Emerg Med Australas 12(1):22-37.

Joint, FAO (2003) Summary and conclusions of the 61st meeting of the Joint FAO/WHO Expert Committee on Food Additives (JECFA). FAO/WHO, Rome.

Kalender Y, Uzunhisarcikli M, Ogutcu A, Acikgoz F, Kalender S (2006) Effects of diazinon on pseudocholinesterase activity and haematological indices in rats: the protective role of vitamin E. Environ Toxicol Pharmacol 22(1):46-51.

Khan IA, Vijaybhasker Reddy B, Mahboob M, Rahman MF, Jamil K (2001) Effects of phosphorothionate on the reproductive system of male rats. J Environ Sci Health B 36(4):445-456.

Khorsandi L, Mirhoseini M, Mohamadpour M, Orazizadeh M, Khaghani S (2013) Effect of curcumin on dexamethasone-induced testicular toxicity in mice. Pharm Biol 51(2):206-212

Kim KS, Lim H-J, Lim JS, Son JY, Lee J, Lee BM, Chang S-C, Kim HS (2018) Curcumin ameliorates cadmium-induced nephrotoxicity in Spraque-Dawley rats. Food Chem Toxicol 114:34-40.
Koltuksuz U, Irmak MK, Karaman A, Uz E, Var A, Özyurt H, Akyol Ö (2000) Testicular nitric oxide levels after unilateral testicular torsion/detorsion in rats pretreated with caffeic acid phenethyl ester. Urol Res 28(6):360-363.

Kumar N, Yadav A, Gulati S, Aggarwal N, Gupta R (2014) Antigenotoxic effect of curcumin and carvacrol against parathion induced DNA damage in cultured human peripheral blood lymphocytes and its relation to GSTM1 and GSTT1 polymorphism. J Toxicol 2014:404236.

Kunati SR, Yang S, William BM, Xu Y (2018) An LC-MS/MS method for simultaneous determination of curcumin, curcumin glucuronide and curcumin sulfate in a phase II clinical trial. J Pharm Biomed Anal 156:189-198.

Lafuente A, Cabaleiro T, Caride A, Esquifino Al (2008) Toxic effects of methoxychlor administered subcutaneously on the hypothalamic-pituitarytesticular axis in adult rats. Food Chem Toxicol 46(5):1570-1575.

Latchoumycandane C, Chitra KC, Mathur PP (2002) The effect of methoxychlor on the epididymal antioxidant system of adult rats. Reprod Toxicol 16(2): $161-172$.

Lawrence RA, Burk RF (1976) Glutathione peroxidase activity in selenium-deficient rat liver. Biochem Biophys Res Commun 71(4):952-958.

Magnusson U, Ljungvall K (2014) Environmental pollutants and dysregulation of male puberty - a comparison among species. Reprod Toxicol 44:23-32.

Maheshwari RK, Singh AK, Gaddipati J, Srimal RC (2006) Multiple biological activities of curcumin: a short review. Life Sci 78(18):2081-2087.

Mahgoub AA, El-Medany AH (2001) Evaluation of chronic exposure of the male rat reproductive system to the insecticide methomyl. Pharmacol Res 44(2): $73-80$.

Maitra SK, Mitra A (2008) Testicular functions and serum titers of LH and testosterone in methyl parathion-fed roseringed parakeets. Ecotoxicol Environ Saf 71(1):236-244.

Masayasu M, Hiroshi Y (1979) A simplified assay method of superoxide dismutase activity for clinical use. Clin Chim Acta 92(3):337-342.

McKinlay R, Plant JA, Bell JNB, Voulvoulis N (2008) Endocrine disrupting pesticides: implications for risk assessment. Environ Int 34(2):168-183.

Mnif W, Hassine AlH, Bouaziz A, Bartegi A, Thomas O, Roig B (2011) Effect of endocrine disruptor pesticides: a review. Int J Environ Res Public Health 8(6): 2265-2303.

Moore PD, Patlolla AK, Tchounwou PB (2011) Cytogenetic evaluation of malathion-induced toxicity in Sprague-Dawley rats. Mut Res/Genet Toxicol Environ Mutagen 725(1):78-82.

Nahid Z, Tavakol HS, Abolfazl GK, Leila M, Negar M, Hamed F, Akram R (2016) Protective role of green tea on malathion-induced testicular oxidative damage in rats. Asian Pac J Reprod 5(1):42-45.

Ojha A, Srivastava N (2014) In vitro studies on organophosphate pesticides induced oxidative DNA damage in rat lymphocytes. Mut Res/Genet Toxicol Environ Mutagen 761:10-17.

Okamura A, Kamijima M, Shibata E, Ohtani K, Takagi K, Ueyama J, Watanabe Y, Omura M, Wang H, Ichihara G (2005) A comprehensive evaluation of the testicular toxicity of dichlorvos in Wistar rats. Toxicology 213(1):129-137.

Oldereid NB, De Angelis P, Wiger R, Clausen OPF (2001) Expression of Bcl-2 family proteins and spontaneous apoptosis in normal human testis. Mol Hum Reprod 7(5):403-408

Pearson JN, Patel M (2016) The role of oxidative stress in organophosphate and nerve agent toxicity. Ann N Y Acad Sci 1378(1):17-24.

Penna-Videau S, Bustos-Obregón E, Cermeño-Vivas JR, Chirino D (2012) Malathion affects spermatogenic proliferation in mouse. Int J Morphol 30(4):1399-1407.

Piper JT, Singhal SS, Salameh MS, Torman RT, Awasthi YC, Awasthi S (1998) Mechanisms of anticarcinogenic properties of curcumin: the effect of curcumin on glutathione linked detoxification enzymes in rat liver. Int J Biochem Cell Biol 30(4):445-456.

Poet TS, Kousba AA, Dennison SL, Timchalk C (2004) Physiologically based pharmacokinetic/pharmacodynamic model for the organophosphorus pesticide diazinon. Neurotoxicology 25(6):1013-1030.

Pope CN (1999) Organophosphorus pesticides: do they all have the same mechanism of toxicity? J Toxicol Environ Health Part B: Crit Rev 2(2):161-181.

Prasad S, Tyagi AK, Aggarwal BB (2014) Recent developments in delivery, bioavailability, absorption and metabolism of curcumin: the golden pigment from golden spice. Cancer Res Treat: official journal of Korean Cancer Association 46(1):2.

Priyadarsini KI, Maity DK, Naik GH, Kumar MS, Unnikrishnan MK, Satav JG, Mohan $\mathrm{H}$ (2003) Role of phenolic $\mathrm{OH}$ and methylene hydrogen on the free radical reactions and antioxidant activity of curcumin. Free Radic Biol Med 35(5): $475-484$. 
Reyes-Gordillo K, Segovia J, Shibayama M, Vergara P, Moreno MG, Muriel P (2007) Curcumin protects against acute liver damage in the rat by inhibiting NF-KB, proinflammatory cytokines production and oxidative stress. Biochimic Biophys Acta (BBA)-General Subjects 1770(6):989-996.

Roohbakhsh A, Moghaddam AH, Delfan KM (2011) Anxiolytic-like effect of testosterone in male rats: GABAC receptors are not involved. Iran J Basic Med Sci 14(4):376.

Rubin C, Esteban E, Kieszak S, Hill RH Jr, Dunlop B, Yacovac R, Trottier J, Boylan K, Tomasewski T, Pearce K (2002) Assessment of human exposure and human health effects after indoor application of methyl parathion in Lorain County, Ohio, 1995-1996. Environ Health Perspect 110(Suppl 6):1047.

Salama M, Lotfy A, Fathy K, Makar M, El-emam M, El-gamal A, El-gamal M, Badawy A, Mohamed WMY, Sobh M (2015) Developmental neurotoxic effects of malathion on 3D neurosphere system. App Transl Genom 7:13-18.

Samuhasaneeto S, Thong-Ngam D, Kulaputana O, Suyasunanont D, Klaikeaw N (2009) Curcumin decreased oxidative stress, inhibited NF- B activation, and improved liver pathology in ethanol-induced liver injury in rats. BioMed Res Int. 2009

Satar S, Sebe A, Topal M, Karcioglu O (2004) Endocrine effects of organophosphate antidotal therapy. Adv Ther 21(5):301-311.

Sepand MR, Soodi M, Hajimehdipoor H, Soleimani M, Sahraei E (2013) Comparison of neuroprotective effects of Melissa officinalis total extract and its acidic and non-acidic fractions against a $\beta$-induced toxicity. Iran J Pharm Res: IJPR 12(2):415.

Sikka SC, Naz RK (1999) Endocrine disruptors and male infertility. In: Naz RK (ed) Endocrine disruptors: effects on male and female reproductive systems. CRC Press, Boca Raton, Florida, pp 225-246.

Slimen S, Saloua GNEF (2014) Oxidative stress and cytotoxic potential of anticholinesterase insecticide, malathion in reproductive toxicology of male adolescent mice after acute exposure. Iran J Basic Med Sci 17(7):522.

Stone WW, Gilliom RJ, Ryberg KR (2014) Pesticides in US streams and rivers: occurrence and trends during 1992-2011. ACS Publications.

Tanaka H, Fujisawa M, Tanaka H, Okada H, Kamidono S (2002) Apoptosis-related proteins in the testes of infertile men with varicocele. BJU Int 89(9):905-909.

Uzun FG, Kalender S, Durak D, Demir F, Kalender Y (2009) Malathion-induced testicular toxicity in male rats and the protective effect of vitamins $C$ and $E$. Food Chem Toxicol 47(8):1903-1908.

Uzunhisarcikli M, Kalender Y, Dirican K, Kalender S, Ogutcu A, Buyukkomurcu F (2007) Acute, subacute and subchronic administration of methyl parathioninduced testicular damage in male rats and protective role of vitamins $C$ and E. Pestic Biochem Physiol 87(2):115-122.

Wright JS (2002) Predicting the antioxidant activity of curcumin and curcuminoids. J Mol Struct THEOCHEM 591(1):207-217.

\section{Submit your manuscript to a SpringerOpen ${ }^{\circ}$ journal and benefit from:}

- Convenient online submission

- Rigorous peer review

- Open access: articles freely available online

- High visibility within the field

- Retaining the copyright to your article

Submit your next manuscript at $\boldsymbol{\nabla}$ springeropen.com 